\title{
Learning from, through and about Differences: A Multiple Case Study on Schools as Practice Grounds for Citizenship
}

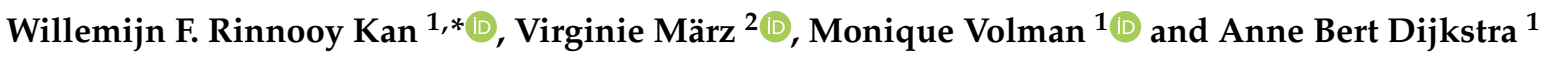 \\ 1 Educational Sciences, Faculty of Social and Behavioural Sciences, University of Amsterdam, \\ 1012 Amsterdam, The Netherlands; m.1.l.volman@uva.nl (M.V.); a.b.dijkstra@uva.nl (A.B.D.) \\ 2 Institute for the Analysis of Change in Contemporary and Historical Societies, Faculty of Psychology and \\ Educational Sciences, Université Catholique de Louvain, 1348 Louvain-la-Neuve, Belgium; \\ virginie.marz@uclouvain.be \\ * Correspondence: W.F.RinnooyKan@uva.nl
}

Citation: Rinnooy Kan, Willemijn F., Virginie März, Monique Volman, and Anne Bert Dijkstra. 2021. Learning from, through and about Differences: A Multiple Case Study on Schools as Practice Grounds for Citizenship. Social Sciences 10: 200. https:// doi.org/10.3390/socsci10060200

Academic Editors: Liyuan Liu,

Steven Donbavand, Bryony Hoskins, Jan Germen Janmaat and

Dimokritos Kavadias

Received: 27 February 2021

Accepted: 21 May 2021

Published: 29 May 2021

Publisher's Note: MDPI stays neutral with regard to jurisdictional claims in published maps and institutional affiliations.

Copyright: (C) 2021 by the authors. Licensee MDPI, Basel, Switzerland. This article is an open access article distributed under the terms and conditions of the Creative Commons Attribution (CC BY) license (https:// creativecommons.org/licenses/by/ $4.0 /)$.

\begin{abstract}
Learning to relate to others that differ from you is one of the central aims of citizenship education. Schools can be understood as practice grounds for citizenship, where students' citizenship is not only influenced by the formal curriculum, but also by their experiences in the context of teacher-student and student-student relations. In this article we therefore investigate how the practice of dealing with difference is enacted in schools. Data were collected through an exploratory multiple case study in four secondary schools, combining interviews and focus groups. Despite the differences between the schools in terms of population and location, in all schools the reflection on the enactment of 'dealing with differences' was limited in scope and depth. 'Being different' was understood primarily in terms of individual characteristics. Furthermore, in all schools there was limited reflection on being different in relation to teachers and the broader community. Finally, relevant differences for citizenship were confined to the category of 'ethnic and cultural diversity'. This article calls for preparing teachers to consider a broader array of differences to practice dealing with differences with their students and to support students in reflecting on the societal implications of being different from each other.
\end{abstract}

Keywords: citizenship education; diversity; differentiation; school as practice ground

\section{Introduction}

Increased participation in education, migration, emancipation have made schools more diverse in their composition and have created new challenges for teachers in the recent decades. The reality of classrooms that are becoming increasingly diverse, e.g., academically and socio-culturally, is an invitation to researchers and practitioners alike to reflect on the most desirable way to deal with these changing teaching and learning environments. As a result, differences between students have been studied from an array of perspectives, often related to individuals' academic capacities, with the goal of increasing educational equality and ensuring equity of access to high-quality learning (e.g., Lindsay 2007; Steenbergen-Hu et al. 2016; Thijs and Verkuyten 2014; Tomlinson et al. 2003). Teachers are well aware of the importance of addressing differences between students; however, many teachers experience attending to those differences as a challenge (Gable et al. 2000; Subban 2006; Tomlinson 2001).

Citizenship education as an educational priority and topic has emerged explicitly in the context of increased societal diversity, especially in terms of their ethnic and cultural composition. One of its main goals is preparing students to function in societies with fellow citizens who differ from them (Banks 2007). During recent decades, an increased focus on the promotion of compulsory citizenship education programs all over the world has been particularly evident (European Commission/EACEA/Eurydice 2017). In educational research, citizenship of adolescents has been conceptualized in different ways (e.g., Banks 
2004; Rychen and Salganik 2003). In this study, following Lawy and Biesta (2006), we approach it as a continuing developmental practice concerned with negotiating the rights and responsibilities that are tied to the membership of the various communities to which people belong. Through this definition of citizenship, schools can be understood as practice grounds for citizenship (Veugelers 2011). Students not only learn about their rights and responsibilities in schools, but practice them through social interactions within the school: using their voice in a student council, solving conflicts, and debating sensitive issues (Flanagan 2013). Learning to deal with differences is at play in all of these examples. Thus, when we understand schools to be practice grounds for citizenship, the differences that students encounter within the classroom and the school as well as the way teachers deal with these differences matter as relevant experiences (Gurin et al. 2004).

In this exploratory multiple case study, our main research question is: how is the practice of dealing with differences enacted in schools? Through our analysis, we aim to make transparent what the abstract notion of learning to 'deal with differences' - as a key element of the ambitions of citizenship education - may actually entail within schools. Consequently, we provide insight into the functioning of schools as practice grounds for citizenship, where citizenship learning takes place beyond the formal citizenship curriculum. This approach allows for new insight for researchers and practitioners, in how we can best profit from the school environment to practice (for) citizenship and in particular, to practice (for) the crucial social skill of dealing with differences.

\section{Conceptual Framework}

\subsection{Dealing with Differences: Categorizing and Group Hierarchy}

The ability to categorize ourselves and others into social groups helps us to make sense of the complexity of the social world (Jenkins 2000). There are many differences that we can use to categorize ourselves and others, for example: gender, socio-economic background, ethnic and cultural background, religion, and socio-emotional development. Schools are typically the place where at least some of these differences are consciously encountered for the first time in children's lives (Flanagan 2013). Additionally, even when these differences are not reflected in the characteristics of the school population itself, they can be introduced and reflected upon by teachers.

Children learn to categorize groups of people through a combination of similarities they observe themselves and labelling of groups by authority figures, for example, their teachers. According to the social identity approach (Tajfel 1978), our positive expectations of in-group members are connected to the human motivation to have a positive self-concept, and as a consequence to believe that 'our' group is a good group. This is not harmful in itself. Young children already categorize and attribute certain positive characteristics to fellow in-group members; however, their social categorization is not automatically negative for the out-group. It simply separates in-group from out-group (Liberman et al. 2017).

One of the main ways information about social categories is transmitted is through language, for example, through the use of generic language in which groups are addressed instead of individuals (i.e., girls always like ... or Moroccan kids prefer ... ). Such use of language reinforces group distinctions and an essentialist understanding of groups (Liberman et al. 2017). If children learn that members of a category share important essences beyond what is observable, an essentialist understanding of groups may develop (Patterson and Bigler 2006). Meanwhile, in society, not all groups are equal, and some groups have a relatively low status in comparison to the "dominant or most valued group or groups in society" (Nesdale and Flesser 2001, p. 506). This perceived hierarchy of groups adds a layer of complexity to dealing with differences, as it suggests that practicing dealing with differences is not the same exercise for those who do and those who do not belong to a dominant group. 


\subsection{The School as a Practice Ground for Dealing with Differences}

School is one of the social environments in which children practice dealing with differences. Practicing dealing with differences can be understood as part of citizenship education. This is in line with a developmental definition of citizenship (Lawy and Biesta 2006), in which schools are understood to be more than places where adolescents formally learn about their future as citizens. Students also informally develop their agency as citizens on a daily basis within the school, through social interactions with other students and teachers (Lawy and Biesta 2006; Torney-Purta and Amadeo 2011). Within the school students learn what being part of a community means, what the consequences and implications of their membership in that community actually are, and how they can best deal with the differences they encounter between themselves and others (Flanagan 2003). Many opportunities for citizenship learning that present themselves within schools are unintentional, not consciously linked with citizenship education (Kahne and Sporte 2009; Kissling 2018). The practice of citizenship happens in relation to others: their fellow students, their teachers, and other members of the professional community (Veugelers 2011). Consequently, insight into the functioning and characteristics of these relations is crucial for understanding how dealing with differences is enacted within the school as a practice ground.

There are different ways in which practicing dealing with differences can take place within the context of the school. One of the ways proposed in the literature is learning to take perspective; positioning oneself in the other's shoes. Research has indicated that the mere presence of others in schools (other in terms of race, social class, gender, for example) is not sufficient to support perspective taking; specific conditions are necessary, for example, equality of status, and normalization and negotiation of conflict (Gurin et al. 2004; Zirkel and Cantor 2004).

Educators act as 'proximate authority figures' who play a significant exemplary role when it comes to experiencing and practicing dealing with differences. In terms of perspective taking, they are the ones that can convey 'equality of status' and model 'the normalization and negotiation of conflict'. Teachers, intentionally and unintentionally, set the example of how students are supposed to deal with others that differ from them. However, the way educators deal with differences also gives students an impression of how authority will deal with people 'like them' (Flanagan 2013). This role as proxy for political authority, is illustrated by a recent study by Bruch and Soss (2018) on different expressions of school authority and their relation to students' civic attitudes. A stricter and more punitive expression of authority resulted in lower trust in government and less political engagement for already-disadvantaged students.

What complicates the enactment of dealing with differences in schools is that for many teachers, their position as proximate authority figure is combined with membership in a dominant group. For members of a dominant group, categorizing can be seen as an innocent act, while for those who perceive themselves as different from a dominant group, being categorized may be experienced as being 'othered' or having their 'being different' confirming their lower status (Borrero et al. 2012). As such for students dealing with differences can also be learning to deal with being different oneself, as difference is inherently relational. Diversifying the teacher population, which has been on the educational agenda for several decades, can help students in several ways in this process. Firstly, a more diverse teacher population could provide mentors and role models for minority students. Furthermore, a more diverse teacher population can provide insight into 'being different' from a dominant group and help students reflect on what that means in society (Cherng and Halpin 2016; Villegas et al. 2012).

\subsection{Different Citizenship Approaches for Different Students}

To complicate matters further, in light of the school as a practice ground for citizenship, it is also relevant to point at a pattern that has been revealed in the research: the lines along which society is stratified, particularly educational level and socio-economic status, 
are mirrored in how citizenship education itself is interpreted for different groups (see, e.g., Nieuwelink et al. 2019; Ten Dam and Volman 2003). Research has shown that not all students have equal access to citizenship learning opportunities. A different type of citizenship may be promoted in the classroom, depending on the educational level of the students. For example, within pre-vocational education, adaptation was found to be the main theme, while pre-university students were more often offered a critical perspective (Ten Dam and Volman 2003). In line with that finding, a recent study showed that pre-vocational students are given fewer opportunities to practice their citizenship in terms of taking part in discussions or debates (Nieuwelink et al. 2019). Yet another study showed that educators in lower socio-economic status school communities had a more local understanding of citizenship, whereas in a school community with a higher socio-economic status, an international or global perspective on citizenship was more common (Goren and Yemini 2017; Sincer et al. 2019; Wood 2015). Finally, Kahne and Middaugh (2008) used the concept of the 'civic opportunity gap' as a way to convey that different students have different opportunities to develop their citizenship competences. Their study, analyzing a Californian sample (2737 students) from the IEA civic education study, showed that academically successful, white and higher socioeconomic status students were presented with more classroom-based civic learning opportunities. As such, while learning to deal with difference in a socially just way is an important goal of citizenship education, research indicates that the way citizenship education itself is enacted in schools often reproduces societies' inequalities.

\subsection{The Present Study}

Our conceptual framework tries to elucidate the complex socializing processes that underly dealing with differences. The school environment, as one of the arenas where these processes take place, provides different opportunities besides curricular content for students to learn how to deal with differences: on the one hand through the opportunities to practice dealing with differences themselves and on the other hand through the modelling of their teachers, as authority figures. When we combine both these aspects, the question remains: how is the practice of dealing with differences enacted in schools as practice grounds for citizenship?

To answer this research question, an exploratory multiple case study was conducted (Yin 2003). This approach allowed us to compare schools and to gain an in-depth understanding of how schools differ in their teachers' practices related to dealing with differences and students' experiences with dealing with difference.

\subsection{Dutch Context}

The study was conducted in four Dutch secondary schools. Schools in the Netherlands have a statutory obligation to promote citizenship, yet schools have a great deal of freedom in fulfilling this obligation (Bron and Thijs 2011). What citizenship implies in this context is very broadly defined in terms of 'promoting active citizenship and social integration' and 'learning to participate in a pluriform democratic society' (Dutch Foundation for Curriculum Development[Stichting Leerplan Ontwikkeling] 2018). This combination of statutory obligation and school autonomy has led to wide variation in school policies and educational practices concerning citizenship education (Dijkstra et al. 2020). In more general terms 'learning to deal with differences' is one of the fifty-eight central aims of secondary education. It is conceptualized in terms of different 'worldviews' and 'lifestyles' and understanding the importance for society to learn to deal 'respectfully with diversity'. ${ }^{1}$

\section{Methods}

\subsection{Sample}

For this study, we selected four schools that differed in terms of student population, tracks offered by the schools, the school's vision (mainstream versus specific pedagogical philosophies), degree of urbanization in the school's location (urban versus rural), and 
school size (small versus large). This maximum variation sampling (Maxwell 2004) was intended to allow for large variation in practices related to dealing with differences. The selection of schools with different track combinations (one versus several tracks) led to variations in academic and sociocultural characteristics and the status of student groups, due to the considerable differences in tracks. All four schools offered pre-vocational education, while two of them also offered pre-university education, allowing us to compare how the schools approached the issue of the handling of the related differences (Table 1).

Table 1. Overview of the cases.

\begin{tabular}{cccc}
\hline Cases & Location & Student Population ${ }^{2}$ & Tracks $^{3}$ \\
\hline $\begin{array}{c}\text { Waldorf } \\
\text { (School 1) } \\
\text { Rural (School 2) } \\
\text { Urban }\end{array}$ & Urban & 800 (approx. 90\% native Dutch) & $\begin{array}{c}\text { Pre-vocational (theory) to } \\
\text { pre-university (3 tracks) }\end{array}$ \\
$\begin{array}{c}\text { Pre-Vocational } \\
\text { (School 3) } \\
\begin{array}{c}\text { Mixed Urban } \\
\text { (School 4) }\end{array}\end{array}$ & Rural & 300 (approx. 95\% native Dutch) & Pre-vocational (job-oriented) (1 track) \\
& Urban & 300 (approx. 5\% native Dutch) & Pre-vocational (theory) (1 track) \\
& Urban & 1600 (approx. 30\% native Dutch) & $\begin{array}{c}\text { Pre-vocational (job-oriented) to } \\
\text { pre-university (4 tracks) }\end{array}$ \\
\hline
\end{tabular}

\subsection{Data Collection}

Data collection took place from September 2014 until February 2015, and included a combination of different data sources: document analysis, observations, and semistructured interviews. A total of 24 interviews (with 16 staff members and 24 students) were conducted by two interviewers, one of whom was the first author. More specifically, two semi-structured interviews were conducted with each school principal, or the team leader who assumed the role of principal $(n=4)$. Additionally, one interview was conducted with the building service workers $(n=4)$, civics teachers $(n=4)$, and mentors $(n=4)$, as well as one focus group session with six pre-vocational students per school (14- to 15-yearolds; $n=24$ ). These students were selected by their mentors, based on our instruction of choosing students that represented the diversity present in the classroom. The mentors we interviewed were the mentors of the students we included, all were responsible for one class of students and all of them were also teachers in the school.

To prepare the interviews, we analyzed the school plan, focusing specifically on information related to citizenship education in general and about dealing with differences in particular. Additionally, we spent a full day in the school and conducted an initial exploratory interview with the school leader. We observed the course of events during breaks and attended at least one class were all students from the focus group were present, as well as being there at the start and end of the school day. We used all of these observations as input for our interviews, but did not include the observations themselves in the data analysis. The interviews with the teachers and building service workers, as well as the first interviews with the school principals, had the following structure: we started with some introductory questions regarding the school vision and practices related to citizenship education and the functioning of the school as community. Next, and in line with the conceptual framework, we focused on understanding how differences were dealt with within the school. More specifically, questions concerned the participants' vision with regard to differences (e.g., In your school plan you mention the diversity of the student population: how would you define diversity?), practices related to differences (e.g., What differences between students are relevant in your practice as a teacher?), and perceived student experience with differences (e.g., Do you see clear groups in your student population? Along what lines do groups exist?). We included the building service workers to gain an inside perspective on the functioning of the school beyond what happened inside the classrooms. In these interviews we did not focus on citizenship education, but we did touch upon all the other themes. The second interview with the principals was usually the last interview in the school which we used to clarify and ask for additional information. 
Students were interviewed during a focus group session. The focus group session started with an open-ended conversation regarding the relations between students at the school and how differences were addressed by teachers (15 min). Next, we presented three short films to the students $(\approx 2$ min each) on groups within the student population, bullying and student teacher relations to further open up conversations about dealing with differences at school. After the first film, we asked for example: Are there groups in the student population? How do you experience these groups? What are characteristics of these groups?

Thus, in the interviews with different members of the school community, both practices and student experiences were addressed; however, the emphasis differed between the structured interviews and the focus group sessions. Through the interviews and focus groups we tried to reconstruct as complete as possible an image of how actors within the school experience and practice dealing with differences.

\subsection{Data Analysis}

All interviews were audio-taped, transcribed verbatim, and interpretatively coded (Miles and Huberman 1994). The data analysis was performed through an iterative process of reading and re-reading of the data, by selecting and coding (data reduction), and by displaying the data in within-case and cross-case matrices (Miles and Huberman 1994). For the coding (in Atlas.ti), we used both 'a priori' and 'in vivo' codes (Bogdan and Biklen 1997). The 'a priori' codes were inspired by our conceptual framework and the 'in vivo' codes were inductive, data-driven codes that arose during analysis, either as a new main code or as a specification of a priori codes in subcodes (see Table 2). The coding and selection of quotes was carried out by the first author. The second and third author provided feedback on the coding and interpretation of the selected quotes.

Table 2. Coding scheme. ${ }^{4}$

\begin{tabular}{|c|c|c|}
\hline Codes & Definition & Subcodes \\
\hline Type of difference & $\begin{array}{l}\text { Statements referring to different } \\
\text { categories of differences }\end{array}$ & $\begin{array}{c}\text { Religion } \\
\text { Gender } \\
\text { Cognitive } \\
\text { Cultural background } \\
\text { Mother tongue (native Dutch/other) } \\
\text { Parents' Socio-Economic Status } \\
\text { Socio-emotional development } \\
\text { Hometown }\end{array}$ \\
\hline Evaluation of difference & $\begin{array}{l}\text { Statements describing difference as being } \\
\text { something positive/negative/irrelevant }\end{array}$ & $\begin{array}{c}\text { Difference_positive (as an asset) } \\
\text { Difference_negative (as a problem) } \\
\text { Difference_blind (as irrelevant) }\end{array}$ \\
\hline Source of difference & $\begin{array}{l}\text { Statements concerning the context and } \\
\text { relation in which difference is understood }\end{array}$ & $\begin{array}{c}\text { Within School_student/student or teacher/student } \\
\text { Outside school_local or national }\end{array}$ \\
\hline $\begin{array}{l}\text { School policy for dealing } \\
\text { with differences }\end{array}$ & $\begin{array}{c}\text { Statements describing school policy and } \\
\text { practices related to dealing with } \\
\text { differences }\end{array}$ & $\begin{array}{l}\text { Differentiation (early tracking) } \\
\text { Diversifying teacher population } \\
\text { Diversity in classroom composition }\end{array}$ \\
\hline $\begin{array}{l}\text { Teacher practices for dealing } \\
\text { with differences }\end{array}$ & $\begin{array}{l}\text { Statements describing teacher practices } \\
\text { related to dealing with differences }\end{array}$ & $\begin{array}{c}\text { Discussing being different in the class } \\
\text { Teacher as role model/example } \\
\text { Teacher as representing authority } \\
\text { Essentializing language } \\
\text { Difference understood in a hierarchical way } \\
\text { Difference understood as an individual characteristic } \\
\text { Difference understood as a relational characteristic }\end{array}$ \\
\hline Goal of practices/policies & $\begin{array}{l}\text { Statements describing the goal of } \\
\text { practices related to dealing with } \\
\text { difference }\end{array}$ & $\begin{array}{c}\text { Interpersonal (as opportunity for students to learn } \\
\text { from each other) } \\
\text { Intrapersonal (as opportunity to learn for the student } \\
\text { who is 'different') } \\
\text { Citizenship (as an opportunity for citizenship } \\
\text { learning) }\end{array}$ \\
\hline
\end{tabular}


The second step of the data analysis consisted of two phases. In the first phase-the within-case analysis - the individual school was taken as our unit of analysis. Transcript fragments with the same codes were grouped and categorized. This resulted in an individual, structured case report for each school, encompassing all of the results of the analysis as well as illustrative interview fragments. The structured case reports described school policy and teacher practices related to dealing with differences as well as the way in which dealing with difference was understood in connection to citizenship education in each school. The structural analogy across the different case reports enabled us to organize the data in a more manageable form, and facilitated comparisons between schools in the second phase. In this phase-the cross-case analysis-we looked for systematic differences, similarities, patterns and processes across the four schools. By comparing the different schools four main themes emerged that were relevant across all four schools: difference as an individual characteristic, the difference between teachers and students, a school internal understanding of difference and a focus on ethnic and cultural diversity in light of citizenship education.

Participation in the study was entirely voluntary. During data collection, the participants were given information about the procedure of data collection and analysis. We explained why we recorded the interviews as well as what would happen with the data (i.e., recording, transcribing, and publishing). At each data collection occasion, we asked them if they had any questions and reminded them that they were free to withdraw at any given point (which none of the participants did). In the process of data collection and data analysis, confidentiality and anonymity were guaranteed. The interview data were anonymized and the results of this study were reported without compromising the identities of the respondents.

\section{Results}

Our results show that the way in which most differences were addressed in the schools limited students' citizenship learning opportunities, although schools differed in the extent to which this happened. Four underlying themes emerged from our analysis. First, differences between students were mainly understood in terms of individual characteristics. Second, the differences between teachers and students were rarely understood to be relevant in terms of students' citizenship learning. Third, the characteristics of the school's student population were taken as a reference point for differences. There was little reflection on how being different from others in society outside of the school might be relevant in terms of citizenship learning. Finally, at all schools, ethnic and cultural differences between students were the only differences that were consciously considered as relevant for practicing dealing with differences as part of citizenship learning, yet the understanding of these types of differences was superficial at all schools.

\subsection{Differences as Individual Characteristics}

Students differed in many ways from each other, for example, in terms of educational level, gender, socio-economic background, and socio-emotional development. These differences were mostly addressed by teachers in an individualized way; educational level, background and so forth were understood as individual characteristics, and in some cases as an obstacle for individual students that teachers could possibly help them overcome.

Regarding differences in educational level, early tracking separated students from the start of their secondary school careers. School 1 was an example of that early separation; students were assigned to different tracks in their first year and thus to different classrooms. Although early tracking is foremost a system feature in the Netherlands, in the first two or three years of secondary school (depending on the tracks), mixing of students is possible. School 1 used to mix students from different tracks, but for several reasons the principal decided to switch to separating students along educational tracks from the very beginning.

Both Schools 2 and 3 served only pre-vocational students. However, these students did differ in other ways, for example, in terms of gender. Gender was an interesting 
characteristic at School 2, which is pre-vocational, because the preparation for a specific field provided the basis for different classes, and these fields are very gendered. More specifically, after the first two years of secondary school there was an all-boys class for technical jobs and an all-girls class for care-related jobs. This resulted in limited interaction between these groups. As students were separated along the lines of their different characteristics, interactions and possibilities for learning from each other and directly experiencing a different perspective were limited.

School 4 was an exception; at this school, differences between students was a key theme, was defined in a very broad sense, and was characterized by a relational approach: "Therefore, learning about differences is not only learning about cognitive differences but also about different capabilities, different cultures, gender, ethnicity, religion, language" (principal, School 4). At this school, students across different educational levels shared classrooms as long as possible, tracking was delayed, which is quite uncommon in the Netherlands, and the population itself was mixed in terms of origin, SES, cultural background, gender, and religion. The presence of diverse others was the norm, and classes were explicitly put together in a way that would ensure a diverse population as possible in each classroom in terms of student background and characteristics. Learning to deal with differences was understood to happen automatically when students encountered differences. Besides the diverse classrooms, other conditions for perspective-taking were present. Classroom practices aimed at dealing with differences mostly concerned creating an open climate, for example, by starting and ending each class in a circle to share: "In the circle we are all equal, there is no one to hide behind", as one of the teachers put it. This open climate was used not only for contact, but also to solve conflicts, as one of the mentors explained. Differences in educational level were also sometimes used within the classroom. One of the teachers remarked that it was a wonderful exercise for pre-university level students to explain a subject to a pre-vocational level student, as according to him, "it helps them to really understand the material". As illustrated by this quote, School 4 was the only school in which differences between students were understood as an explicit asset in their relationships.

At the same time, at three (Schools 1,2 and 4) of the four schools, teachers reflected on the quality of their care for individual students' needs in terms of socio-emotional wellbeing. For example, at School 2 the principal took pride in the school for having a well-developed system of mentors and care coordinators to support individual students in their specific needs related to their socio-emotional development. Additionally, at School 1 , the principal described the continual process of trying to figure out the different needs of individual students and how they could best be supported as part of the process of "becoming who you are".

When differences between students are only understood in terms of how best to meet the individual needs that might be associated with those differences, the consequence for the school as a practice ground is that students are not invited to actively practice dealing with differences themselves. They are treated in a way that addresses their individual way of 'being different' but they are rarely invited to deal with differences between themselves and others, and to reflect on the meaning and impact of differing from each other. At all schools a myriad of opportunities to practice dealing with differences, for example through the experience of different perspectives, thus remained underused.

\subsection{Different from Your Teacher}

Students did not just differ from each other; in general, they also shared few characteristics with their teachers. This was especially true in pre-vocational classrooms, where teachers all completed a higher education program, something the majority of their students probably never will do. Teachers in our sample were also predominantly white. At School 1 (the Waldorf school), however, students and teachers were similar on many counts: in background, in ideology, and in socio-economic status. In general, the teacher population was hardly ever understood as a significant part of the school population 
when differences were reflected upon, and consequently the differences between teachers and students were ignored as an opportunity for reflection and citizenship learning for students.

At School 3, however, the analysis showed that diversity in the teacher population was considered important; the ambition was to have a teacher population that reflected the surrounding environment within which the school was located.

That is a considered choice [to have a diverse teacher population], also in view of our environment. But now it is no longer a considered choice, it is more the normal state of affairs. Because half of this city, 50-50 obviously, consists of ... and it would, of course, be idiotic if in a big city in which there are different cultures, and this is true for the Netherlands as a whole, that all your teachers are still native Dutch only. (team leader, School 3)

However, even at this school, beyond aiming at a diverse teacher population, there was no vision as to what this diversity should lead to, or what practices within the school should contribute to bringing about the desired effect. However, there seemed to be the implicit idea at this school that teachers can act as role models. Additionally, indeed, at all schools, students looked for similarities with their teachers. The teachers who were understood to be part of their in-group were treated differently by students. At School 3 , one of the teachers, who wore a headscarf, talked about being confided in by students looking for advice on how to interpret some of the religious laws. At School 4, the building service worker described a similar dynamic as he explained that after students realized that he had a Surinamese background (which was not obvious at first sight), this helped him to interact with many of them in a friendly and interested manner.

Additionally, while similarities between members of the professional community seemed to be an invitation to connect, differences seemed to invite the exact opposite. For example, at School 3, a teacher who differed from most of her students in terms of ethnic background and educational level talked about how shocked she was by the level of mistrust the students had in her intentions, accusing her of "wanting them to fail".

That effect of detecting differences seemed to work both ways. Differences between teachers and students were seldom used as an invitation to collective reflection. For example, one of the civics teachers (School 4) shared his frustration regarding the garbage on the streets after a bike ride through the neighborhood where most students live, and remarked: "Additionally, then one must reach the conclusion that not everyone has the same intrinsic motivation for citizenship as you and I". In terms of citizenship learning, this illustrates the perceived difference in starting point between teacher and student, but it did not invite the teacher to use this observation to reflect on it together with his students: is this about motivation? What do the students think? What could be reason for the trash on the streets? The same teacher talked about having to lower his expectations with some of his students, and learning to accept that when a student has two or more homes the chances are a bit better for things to become lost. This observation resulted in a changed, more tolerant attitude towards students, but did not actively include the students, for example, through a discussion on the broader implications of divorce or the effects of multiple caregivers on children.

In terms of the school as a practice ground, this illustrated the importance of teacher reflexivity on their position in relation to their students as well as to the dominant group. This is a complex skill that most of them probably were not trained for as part as their teacher education. Besides the difference in position within the school, possibly the fact that teachers are representatives of the dominant group plays a role here: they may have unconsciously considered themselves 'the norm' and their students as 'different'. However, teachers' lack of reflection on their position diminished the opportunity for students to learn about the significance of hierarchies of groups in society, as well as about their own relative position and its implication. At the same time, it became clear that the students experienced relationships with their teachers, both positively and negatively, as relevant and as having an influence on their learning to deal with differences. 


\subsection{Being Different: Within and Outside of the School}

Learning to deal with differences is also learning to deal with being different. The student population within the school seemed to serve as the only reference point for difference. We rarely encountered a broader reflection on what being part of the specific population the school serves implies in the context of the broader society.

At School 2, 'the city' was far away, not only geographically. "These students do not move far beyond the tractor", the civics teacher remarked. He was very focused on giving the students pride in their local identity, for example, by sometimes using the local dialect. Other teachers seemed less occupied with the question of identity; they were more concerned with the students obtaining their diplomas and keeping the students in school. Citizenship at this school was understood in a local sense: "Contributing to the local community" and "Making the world around you a bit better" (civics teacher 1, School 2).

The other civics teacher the rural school, School 2, explicitly aimed at making these students' world larger: "They must understand that the world is bigger than their small village" (team leader and civics teacher, School 2). This example illustrates the complexity of finding 'the right way' to deal with the perceived distance between the student population and the dominant group. At this school, two teachers used different approaches: the first civics teacher stimulated local pride, strengthening the sense of community within the school, while the other civics teacher tried to move beyond the local, trying to make the 'normal' a bit less narrow by encouraging students to take a broader perspective.

At School 3, there was the same tendency to using the students' background as a reference point for what is 'normal'. Teachers dealt with the fact that many of their students differed from the dominant group in a similar fashion: they connected this 'being different' to characteristics of the local community. Most of the students had an Islamic background; at this school, that was just "normal". This is illustrated by the fact that the school emptied out during Islamic holidays and teachers did something fun with the few non-Islamic students. Citizenship was also understood in a local way at this school; the national level was explicitly reduced to that of the city where the school was situated: "When we are talking about the Netherlands, we are actually mainly referring to [city]" (school leader, School 3). In terms of the school as a practice ground, this implied that students mostly practiced for the world they already know, a world that is nearby.

School 1, the Waldorf school, illustrated the costs, in terms of citizenship learning opportunities related to dealing with differences, of a school community where ideological characteristics are shared by students and teachers. Despite having a completely different population than the other three schools, it illustrated the presence of the implicit reference category of the dominant group in a different way. Furthermore, what was different about the population at this school was that it did not reflect the diversity of the urban context it was located within, whereas the other three schools mirrored characteristics of the members of the surrounding community. At this school, the perceived connection of the school community to the dominant, white, group was frowned upon. Throughout the professional community frustration was expressed at being reduced to working at a 'white school', a term used in the Netherlands to describe a school that has a predominantly native Dutch population. The association diminished the importance of what they themselves understood to be their shared identity; for them it was the ideology they shared, not their skin color. The consequence of the exclusive character of the school, a relatively homogeneous population, was negatively discussed within the professional community, but there was little reflection on the possible role that the shared ideology could play in maintaining that exclusive character. However, students did consciously experience its 'othering' implications and did experience how the rules worked differently for people 'like them'.

Student A: There was this boy (... ), who has a foreign background, and who is not your stereotypical 'Waldorf' child but, like, he was a student here, and he was such a pain in his class, but when he did something it was regarded as ten times more serious than for someone else. If a real 'Waldorf' child did that, it was judged upon in a very mild way, 
and if he did something like that, the reaction immediately was "If this goes on, you will be suspended". So, actually, I often think that if you are not completely what they want you to be, they may still, well, how shall I put it ...

Student C: begin to hate you.

Student A: Yes, it may be that this school will start to hate you.

(focus group students, School 1)

The openness of the within-school relations was cherished by teachers, and the distance from the outside world was accepted as part of the ambition to keep the shared ideological roots intact. The effect was comparable to that at Schools 2 and 3; the practice ground for citizenship remained narrow.

Teachers and school leaders at all three of these schools tended to use the characteristics of their student population as a reference point for difference, possibly as a means to make students feel included and connected to the school. What the examples illustrate is that to gain greater insight into how dealing with differences is enacted within schools, an important aspect to consider is the presence and effect of using the within-school student population as a reference point for what is 'normal'. While teachers might have focused on what was shared from the perspective of community, a relatively homogenous environment complicated learning to deal with differences. Despite the positive motivation behind it, this process limits the opportunities of students to practice dealing with differences and dealing with being different. It also limits the scope of their understanding of their relative position in the larger society, a missed opportunity in terms of citizenship learning. At School 4, the mere presence of a diverse student population and the fact that this diversity was understood and used as an asset created a different starting point for a shared norm. Here, diversity was normalized, instead of relative homogeneity.

\subsection{Diversity, Not Difference}

While principals and teachers ignored many types of difference as opportunities to practice dealing with differences, they all discussed and reflected upon ethnic and cultural differences, usually under the header of 'diversity'. This type of difference was also the only type of difference that was explicitly connected to citizenship education at all schools.

At School 1, the Waldorf school, ethnic and cultural diversity was almost entirely absent within the school population. The principal described the homogenizing effect of attending the school on an already homogenous population: "students seem to get more and more alike during their time here". There was a clear wish for increased diversity, but little reflection on how minority students could be made to feel welcome. To compensate for the lack of this type of diversity a 'World Day' was organized every year, where "people with different cultural backgrounds, for example Surinamese, Hindu and Indonesian" were invited to talk about 'their culture'. In terms of the school as a practice ground one might say that this confirms 'other' cultures as being far removed from the daily lives of students, and exoticized them rather than creating opportunities to practice taking a different perspective.

Citizenship education at this school was focused on 'becoming who you are'; supporting self-expression was the main goal, in this context. Meanwhile, "unworldly", disconnected to the reality of the 'real world', was what some students in the school called themselves:

However, I do feel that there are few people from different backgrounds at our school, and people thus more easily shy away from other cultures and such. And that is not a good thing, in my opinion, because the whole world is a mix, like, and it is also good to get to know other cultures and not be afraid of them. (... ) And later you are simply in the real world and there will be other cultures all around you and I do feel that you should learn about this, like, earlier. (student, School 1)

While some students qualified their being 'unworldly' as somewhat problematic, they did not consider it their school's task to help them become more worldly. The principal 
realized that this inward look did contribute to the strong sense of community in the school. However, at the same time, it limited students' exposure to the outside world, which is different not only in its greater diversity, but also, for example, in having stricter rules.

At School 2, the rural school, ethnic and cultural diversity were also almost entirely absent within the school population, but the principal, who also taught civics, stressed that this type of diversity was nevertheless an important theme in the school, because students were often very stigmatizing when they talked about immigrants. The principal struggled with creating an awareness that the world is larger than the small villages the students come from, and also felt that the lack of ethnic and cultural diversity within the school was a limiting factor in terms of citizenship education. During his civics classes, he used the significance of the local community to help students reflect on the experience of refugees, by discussing what had happened in the area during World War II, when many of the ancestors of the students had to flee themselves. Even though the school population provided little opportunity to practice dealing with ethnic and cultural diversity, this was an attempt to at least nurture compassion and perspective-taking in light of encountering differences.

The two schools with a population that was not predominantly native Dutch dealt with this fact in very different ways. At School 4, ethnic and cultural diversity was celebrated, as an important cornerstone of the school's identity. Diversity was mostly approached as an opportunity to learn from each other, and the school's responsibility to be an emancipating institution was emphasized. However, at this school, teachers also categorized students by their ethnic or cultural background: "All the Surinamese kids ... ", "These kids have music in them, they are so different from the Turkish and Moroccan kids ..." ". This way of speaking could reinforce essentialist notions of cultural identity and influenced what students learnt about being ethnically and culturally different from the native Dutch population. Students themselves said they appreciated the fact that their school was so diverse, because other kids could teach you about "their culture, for example what they eat", reflecting a superficial understanding of the implications of ethnic and cultural differences.

The student population at School 3 was rather homogeneous non-native Dutch, mainly of Moroccan and Turkish descent, and the great majority of students shared an Islamic background. In terms of the school as a practice ground for citizenship, there was a strong focus on adaptation and rule obedience; for example, speaking any other language than Dutch was strictly forbidden, even in the hallways. The fact that the majority of the students in this school belonged to a minority in society, ethnically different from the dominant group, was not reflected upon or used. One of the teachers noted that students from a minority group within the school, such as those with a Hindu or atheist background, were sometimes hesitant when she asked them to speak their mind on what they believe: "They are afraid the others will find them strange" (civics teacher, School 3).

Schools 3 and 4 illustrate that the mere presence of an ethnically diverse or minoritized student population did not automatically result in more nuanced reflection on what being different implies or what being part of a minority implies. However, at the two other schools with a more homogeneous native Dutch population, the assumption did seem to be that a more ethnically diverse population would lead to more nuanced reflection.

To conclude, at all schools, despite their differences in population, the understanding of ethnic and cultural differences, usually labelled as 'diversity', was quite superficial, mentioning only surface elements. This superficial understanding was visible in the schools' practices and student experiences. This was the case even at schools that had ethnically and culturally diverse populations. In terms of the school as a practice ground, despite the importance attached to this type of difference, students seemed to learn little about its complex implications.

\section{Discussion}

This study explored how the practice of dealing with differences is enacted in schools as practice grounds for citizenship. Our main finding is that the reflection on the enactment 
of dealing with differences was limited in scope and depth within the schools that were studied. However, schools did differ in the extent to which and the way this happened. The differences between schools were related to four underlying themes.

The first theme specifically concerns the individual, instead of relational, understanding of difference. Differences between students were mainly understood in terms of individual characteristics. Differences were addressed in a way that focused on improving students' individual learning trajectories instead of being seen as an opportunity to practice dealing with differences in relation with other students. This is in line with what other authors have pointed out concerning citizenship education in general, where a lack of 'good citizenship' has also been framed in individual terms, as an individual characteristic and problem to be solved through education instead of as a contexualized and relational practice (Biesta and Lawy 2006).

The second theme was the lack of reflection on the difference between students and teachers and, as a consequence, the missed opportunities to practice with dealing with these differences. Our study illustrated that the enactment of dealing with differences that supports citizenship learning opportunities for students asks for specific competencies of teachers. Teachers at all four schools showed little reflexivity on their own positionality as (predominantly) members of the white, native Dutch majority (Martin and Van Gunten 2002). As such, they did not make use of the opportunities to address the societal implications of differences and model possible alternatives and as such contribute to the citizenship learning of their students. Furthermore, while the few minority teachers showed interest in their role as possible role models, other teachers reflected hardly at all on their position as representing authority outside of their classrooms (Flanagan 2003). Other research confirms that there is work to be done in this realm in terms of teacher training. To promote a more relational and contextualized understanding of difference in particular, Goodman (2011) proposes that the only way to do justice to difference is to move beyond 'accepting, appreciating and understanding cultural differences' (p. 3) and to seek social justice by addressing issues of 'privilege and power'(p. 4). To do this, teachers must be taught to reflect on their own position of power as a starting point to help their students in this complex process (Paul-Binyamin and Haj-Yehia 2019). Additionally, a more inclusive approach to relevant differences instead of the narrow focus on ethnic and cultural difference could also contribute to better practices, as advantage and disadvantage, power and privilege, are at play in the context of many differences (e.g., differences in gender, ability, age and sexual identity; Knowles and Clark 2018).

Thirdly, defining difference was primarily done using the characteristics of the school's student population as a reference point. The broader societal context was hardly understood as a reference point for difference. As such, there was little reflection on how being different from others in society outside of the school might be relevant in terms of citizenship learning. The inward focus on the school and the corresponding sense of school community were (unconsciously) prioritized over the introduction of the outside world and its complex relation with difference (Sincer 2021). As such, citizenship learning was primarily focused on a world that students already knew, a world nearby. It is clear that doing justice to diversity while supporting a sense of unity is a complicated task. As a solution, Shields (2000) proposed the notion of schools as 'communities of difference', in which both a sense of (school) community and the value of diversity are combined. This is an approach to community where what is shared is built upon reflection on how best to deal with differences, in all their nuances, within the school. This can be understood as an invitation to move beyond the narrow focus on ethnic and cultural differences and to embrace a broader understanding of relevant differences, including but not limited to educational level, gender identity, religious background, socio-economic status and socio-emotional development as possible differences that are relevant in students' daily lives in the larger society. In terms of the school as a practice ground for citizenship, this approach could enable an enactment of dealing with differences that supports a much 
broader array of citizenship learning opportunities than we encountered in the schools that were part of this study.

Finally, our analysis shows that 'ethnicity and/or culture as difference' is understood as the most pressing difference within schools in the context of citizenship education. This was especially true in the schools that lacked this type of difference within the student population. Despite the relevance attached to it for all schools, differences within this category were treated in a superficial way, for example, with a focus on tangible differences such as food preference or music, and essentializing language was often used to describe these differences. This limited nuanced reflection on the meaning and implications of ethnic and cultural diversity, and the way differences in this category interact with other differences. The presence of diverse others within the school community in this category was not sufficient to avoid these pitfalls, although within schools that lacked this type of difference that seemed to be the idea: their population not their practices limited the opportunity to learn to deal with ethnic and cultural diversity (Zirkel and Cantor 2004). This seems to hold true not only for citizenship education, but within the discourse on citizenship in general (Bauböck and Rundell 1998; Bloemraad et al. 2008), which is not surprising as citizenship education and citizenship learning are connected to broader societal understandings of citizenship (e.g., Banks and Diem 2008). Here, we also recognize the tension between a desire for unity and the reality of diversity. The focus on 'a shared culture', defined along the lines of the culture of the mainstream or dominant groups in society, as the cornerstone of how citizenship in general is understood is an illustration of the first aspect (Alba and Duyvendak 2019). Meanwhile, the multicultural or even 'super-diverse' character of most Western nations has become a given. The dual forces of a narrow understanding of citizenship in general and the desire by an increasingly diverse population to feel included and acknowledged as citizens, create a complex playing field for educators in the realm of citizenship education; they are expected to prepare their students for a world in which both these forces are present. As Ben-Porath (2012) described it using her framework of 'citizenship as shared fate':

Schools in democratic societies are charged with responding to the multiplicity of affiliations, preferences, ideologies, languages, values, and memberships. They are expected to celebrate the diversity of the student body, but also to minimize it by developing civic capacity and a host of shared dimensions, including language(s), civic knowledge, academic competency, and patriotic sentiments. (p. 328)

The response from the perspective of citizenship education to this increasingly pluriform context differs. Some authors have proposed a more global approach to citizenship education (e.g., Veugelers 2011), one that focuses on shared human rights (e.g., Alderson 2016) or one that specifically centers on cultural rights (e.g., Banks 2004). What these approaches share is a critique of the lack of reflection on hierarchy and power between different groups in society in the context of citizenship and citizenship education, a relevant critique in light of the results of this study.

\section{Conclusions}

Learning to deal with differences is one of the main themes in the context of schools as practice grounds for citizenship. Despite limitations such as early tracking and school segregation, schools can make use of a broad array of opportunities for students to learn from, through and about differences, their implications and different ways to deal with them. In sum, this study showed that the way dealing with differences was enacted limited the citizenship learning opportunities of students. A broader understanding of relevant differences in schools, reflection on the fact that difference is inherently relational, as it is a characteristic of a relationship, as well as more reflection on the societal hierarchy related to differences by teachers would all contribute to increasing the quantity and quality of these opportunities.

Practicing dealing with differences can be a conscious as well as an unconscious process. In this study, we have primarily relied on interviews to gain insight into how dealing 
with differences was enacted. This method allowed us to compare four different schools. However, to gain insight into the subtler processes by which dealing with differences is modeled by teachers, for example, an ethnographic approach might be a more appropriate method. Furthermore, schools are not islands; dealing with differences is also practiced by teachers and students outside of the school and their practices and understandings are thereby also influenced by peers, the media, and the community of which they are a part. In this study, we focused exclusively on the school. For future research, it would be interesting to find out how students perceive the weight of the school's influence in comparison to the influence of their peers, family, and media. Finally, we touched upon similar topics in all interviews. However, in some interviews we spoke more elaborately about some of the topics than in others. This was especially true for the focus group sessions with the students, in which some topics were difficult to discuss in some of the groups, and probing did not always result in a deeper conversation. In scientific research, more insight is needed into (different groups of) students' experiences with how differences are dealt with within their schools, in order to understand the effect of different approaches. Another important question for future studies is how different ways of dealing with differences affect civic and democratic attitudes and behaviors of students outside the classroom.

The results of this study underline the importance of teacher competencies for dealing with differences in the context of schools as practice grounds for citizenship, and serve as an invitation to teacher educators to reflect on what practices will best serve the development of these competencies. This starts with the affirmation that how dealing with differences is enacted by teachers matters for the content and quality of the citizenship learning opportunities of their students. Further research on effective teacher training in this domain is necessary, especially because what is effective might differ for different teachers and different (groups of) students, as well as within different national contexts (Leeman and Reid 2006; Wubbels et al. 2006; Seeberg 2003). Furthermore, for future research, it would be interesting to see if the notion of 'schools as communities of difference' in practice, if embraced by the professional community at a school, indeed contributes to a greater scope and depth of citizenship learning opportunities for students in the realm of dealing with differences. This interpretation of community might provide a crucial starting point to address the tension present within citizenship, and citizenship education, between craving unity and addressing diversity in a socially just way.

Author Contributions: Conceptualization, W.F.R.K., V.M., M.V. and A.B.D.; methodology, W.F.R.K., V.M. and M.V.; software, W.F.R.K.; validation, W.F.R.K., V.M. and M.V.; formal analysis, W.F.R.K.; investigation, W.F.R.K.; resources and data curation, W.F.R.K.; writing—original draft preparation, W.F.R.K.; writing-review and editing, V.M. and M.V.; supervision, V.M., M.V. and A.B.D.; project administration, A.B.D.; funding acquisition, A.B.D. All authors have read and agreed to the published version of the manuscript.

Funding: This research was funded by the Dutch Organization for Scientific Research (NOW): Grant number 411-12-035.

Institutional Review Board Statement: Ethical review and approval were waived for this study, due to the fact that at our faculty during the period of data collection (in 2016) obtaining approval from an ethical review board was not yet common practice. In the Netherlands only in 2018 a general and shared 'Code of Ethics for Research in the Social and Behavioral Sciences involving Human Participants' was published and signed by the deans of all Dutch Social Sciences faculties. We have however adhered to common ethical guidelines such as consent of participants, the possibility to withdraw at any moment and entirely voluntary participation.

Informed Consent Statement: Informed consent was obtained from the subjects involved in the study.

Data Availability Statement: Not applicable.

Conflicts of Interest: The authors declare no conflict of interest. 


\section{Notes}

1 As stated in the 'Decree Key Aims of Secondary Education' 7 June 2006 by the Dutch Ministry of Education, Culture and Science (nr. WJZ/2006/4655 (3805). Available online: https:/ / wetten.overheid.nl/BWBR0019945/2012-12-01 (accessed on 20 February 2021).

2 The percentage of native Dutch students is based on an estimation by school principals.

3 After completing primary school (age 11/12), students are placed in one of the three tracks within the Dutch school system: pre-vocational education (vmbo), general secondary education (havo) and pre-university education (vwo). Pre-vocational schools have job-oriented tracks (vmbo-b/k) and theory-oriented tracks (vmbo-tl).

4. The 'in vivo' codes and subcodes are in italics.

\section{References}

Alba, Richard, and Jan Willem Duyvendak. 2019. What about the mainstream? Assimilation in super-diverse times. Ethnic and Racial Studies 42: 105-24. [CrossRef]

Alderson, Priscilla. 2016. International human rights, citizenship education, and critical realism. London Review of Education 14: 1-12. [CrossRef]

Banks, James A. 2004. Teaching for social justice, diversity, and citizenship in a global world. The Educational Forum 68: $296-305$. [CrossRef]

Banks, James A. 2007. Diversity and Citizenship Education: Global Perspectives. Indianapolis: Jossey-Bass.

Banks, James A., and Nguyen Diem. 2008. Diversity and citizenship education. In Handbook of Research in Social Studies Education. Edited by Linda S. Levstik and Cynthia A. Tyson. New York: Routledge, pp. 137-49.

Bauböck, Rainer, and John Rundell, eds. 1998. Blurred Boundaries: Migration, Ethnicity, Citizenship. New York: Routledge.

Ben-Porath, Sigal. 2012. Citizenship as shared fate: Education for membership in a diverse democracy. Educational Theory 62: 381-95. [CrossRef]

Biesta, Gert, and Robert Lawy. 2006. From teaching citizenship to learning democracy: Overcoming individualism in research, policy and practice. Cambridge Journal of Education 36: 63-79. [CrossRef]

Bloemraad, Irene, Anna Korteweg, and Gökçe Yurdakul. 2008. Citizenship and immigration: Multiculturalism, assimilation, and challenges to the nation-state. Annual Review of Sociology 34: 153-79. [CrossRef]

Bogdan, Robert, and Sari Knopp Biklen. 1997. Qualitative Research for Education. Boston: Allyn \& Bacon.

Borrero, Noah E., Christine J. Yeh, Crivir I. Cruz, and Jolene Suda. 2012. School as a context for "othering" youth and promoting cultural assets. Teachers College Record 114: 1-37.

Bron, Jeroen, and Annette Thijs. 2011. Leaving it to the schools: Citizenship, diversity and human rights education in the Netherlands. Educational Research 53: 123-36. [CrossRef]

Bruch, Sarah K., and Joe Soss. 2018. Schooling as a formative political experience: Authority relations and the education of citizens. Perspectives on Politics 16: 36-57. [CrossRef]

Cherng, Hua-Yu Sebastian, and Peter F. Halpin. 2016. The importance of minority teachers: Student perceptions of minority versus White teachers. Educational Researcher 45: 407-20. [CrossRef]

Dijkstra, Anne Bert, Geert Ten Dam, and Anke Munniksma. 2020. Inequality in citizenship competences. Citizenship education and policy in the Netherlands. In The IEA Civic and Citizenship Education Studies: Contributions to Understanding the Process of Preparing Citizens. Edited by B. Malak Minkiewicz and J. Torney-Purta. Berlin: Springer.

Dutch Foundation for Curriculum Development [Stichting Leerplan Ontwikkeling]. 2018. Starting Note Citizenship [Startnotitie Burgerschap]. Available online: https:/ / curriculum.nu/wp-content/uploads/2018/03/Startnotitie-Burgerschap.pdf (accessed on 20 January 2021).

European Commission/EACEA/Eurydice. 2017. Citizenship Education at School in Europe-2017. Brussels: Eurydice.

Flanagan, Constance A. 2003. Developmental roots of political engagement. PS: Political Science and Politics 36: 257-62. [CrossRef]

Flanagan, Constance A. 2013. Teenage Citizens: The Political Theories of the Young. Cambridge: Harvard University Press.

Gable, Robert A., Jo M. Hendrickson, Stephen W. Tonelson, and Richard Van Acker. 2000. Changing disciplinary and instructional practices in the middle school to address IDEA. The Clearing House 73: 205-8. [CrossRef]

Goodman, Diane J. 2011. Promoting Diversity and Social Justice: Educating People from Privileged Groups. New York: Routledge.

Goren, Heela, and Miri Yemini. 2017. The global citizenship education gap: Teacher perceptions of the relationship between global citizenship education and students' socio-economic status. Teaching and Teacher Education 67: 9-22. [CrossRef]

Gurin, Patricia, Biren (Ratnesh) A. Nagda, and Gretchen E. Lopez. 2004. The benefits of diversity in education for democratic citizenship. Journal of Social Issues 60: 17-34. [CrossRef]

Jenkins, Richard. 2000. Categorization: Identity, social process and epistemology. Current Sociology 48: 7-25. [CrossRef]

Kahne, Joseph, and Ellen Middaugh. 2008. Democracy for Some: The Civic Opportunity Gap in High School. Circle Working Paper 59. College Park: Center for Information and Research on Civic Learning and Engagement (CIRCLE), University of Maryland.

Kahne, Joseph, and Susan Sporte. 2009. Developing citizens: The impact of civic learning opportunities on students' commitment to civic participation. In Civic Education and Youth Political Participation. Edited by M. Print and H. Milner. Leiden: Brill Sense, pp. 159-86. 
Kissling, Mark T. 2018. Social studies and beyond: Attending to informal citizenship education in schools. Social Studies Research and Practice 13: 289-300. [CrossRef]

Knowles, Ryan T., and Christopher H. Clark. 2018. How common is the common good? Moving beyond idealistic notions of deliberative democracy in education. Teaching and Teacher Education 71: 12-23. [CrossRef]

Lawy, Robert, and Gert Biesta. 2006. Citizenship-as-practice: The educational implications of an inclusive and relational understanding of citizenship. British Journal of Educational Studies 54: 34-50. [CrossRef]

Leeman, Yvonne, and Carol Reid. 2006. Multi/intercultural education in Australia and the Netherlands. Compare: A Journal of Comparative and International Education 36: 57-72. [CrossRef]

Liberman, Zoe, Amanda L. Woodward, and Katherine D. Kinzler. 2017. The origins of social categorization. Trends in Cognitive Sciences 21: 556-68. [CrossRef]

Lindsay, Geoff. 2007. Annual review: Educational psychology and the effectiveness of inclusive education/mainstreaming. British Journal of Educational Psychology 77: 1-24. [CrossRef]

Martin, Renée J., and Dawn M. Van Gunten. 2002. Reflected identities: Applying positionality and multicultural social reconstructionism in teacher education. Journal of Teacher Education 53: 44-54. [CrossRef]

Maxwell, Joseph A. 2004. Using qualitative methods for causal explanation. Field Methods 16: 243-64. [CrossRef]

Miles, Matthew B., and A. Michael Huberman. 1994. Qualitative Data Analysis: An Expanded Sourcebook. Beverly Hills: Sage Publications.

Nesdale, Drew, and Debbie Flesser. 2001. Social identity and the development of children's group attitudes. Child Development 72: 506-17. [CrossRef] [PubMed]

Nieuwelink, Hessel, Paul Dekker, and Geert ten Dam. 2019. Compensating or reproducing? Students from different educational tracks and the role of school in experiencing democratic citizenship. Cambridge Journal of Education 49: 275-92. [CrossRef]

Patterson, Meagan M., and Rebecca S. Bigler. 2006. Preschool children's attention to environmental messages about groups: Social categorization and the origins of intergroup bias. Child Development 77: 847-60. [CrossRef] [PubMed]

Paul-Binyamin, Ilana, and Kussai Haj-Yehia. 2019. Multicultural education in teacher education: Shared experience and awareness of power relations as a prerequisite for conflictual identities dialogue in Israel. Teaching and Teacher Education 85: 249-59. [CrossRef]

Rychen, Dominique S., and Laura H. Salganik, eds. 2003. Key Competencies for a Successful Life and Well-Functioning Society. Cambridge: Hogrefe Publishing.

Seeberg, Marie Louise. 2003. Dealing with Difference: Two Classrooms, Two Countries. Oslo: NOVA-Norwegian Social Research.

Shields, Carolyn M. 2000. Learning from difference: Considerations for schools as communities. Curriculum Inquiry 30: $275-94$. [CrossRef]

Sincer, Isil. 2021. Diverse School, Diverse Citizens? Teaching and Learning Citizenship in Schools with Varying Student Populations. Ph.D. dissertation, Erasmus University, Rotterdam, The Netherlands.

Sincer, Isil, Sabine Severiens, and Monique Volman. 2019. Teaching diversity in citizenship education: Context-related teacher understandings and practices. Teaching and Teacher Education 78: 183-92. [CrossRef]

Steenbergen-Hu, Saiying, Matthew C. Makel, and Paula Olszewski-Kubilius. 2016. What one hundred years of research says about the effects of ability grouping and acceleration on $\mathrm{K}-12$ students' academic achievement: Findings of two second-order meta-analyses. Review of Educational Research 86: 849-99. [CrossRef]

Subban, Pearl. 2006. Differentiated instruction: A research basis. International Education Journal 7: 935-47.

Tajfel, Henri, ed. 1978. Differentiation between Social Groups: Studies in the Social Psychology of Intergroup Relations. Cambridge: Academic Press.

Ten Dam, Geert, and Monique Volman. 2003. A life jacket or an art of living: Inequality in social competence education. Curriculum Inquiry 33: 117-37. [CrossRef]

Thijs, Jochem, and Maykel Verkuyten. 2014. School ethnic diversity and students' interethnic relations. British Journal of Educational Psychology 84: 1-21. [CrossRef] [PubMed]

Tomlinson, Carol A. 2001. How to Differentiate Instruction in Mixed-Ability Classrooms. Alexandria: ASCD.

Tomlinson, Carol A., Catherine Brighton, Holly Hertberg, Carolyn M. Callahan, Tonya R. Moon, Kay Brimijoin, Lynda A. Conover, and Timothy Reynolds. 2003. Differentiating instruction in response to student readiness, interest, and learning profile in academically diverse classrooms: A review of literature. Journal for the Education of the Gifted 27: 119-45. [CrossRef]

Torney-Purta, Judith, and Jo-Ann Amadeo. 2011. Participatory niches for emergent citizenship in early adolescence: An international perspective. The Annals of the American Academy of Political and Social Science 633: 180-200. [CrossRef]

Veugelers, Wiel. 2011. Theory and practice of citizenship education. The case of policy, science and education in the Netherlands. Revista de Educación 1: 209-224.

Villegas, Ana Maria, Kathryn Strom, and Tamara Lucas. 2012. Closing the racial/ethnic gap between students of color and their teachers: An elusive goal. Equity \& Excellence in Education 45: 283-301.

Wood, Bronwyn Elizabeth. 2015. Teacher interpretations of 'active' citizenship curricula: Shared identities and spatial orientations. In International Handbook of Progressive Education. Edited by Mustafa Yunus Eryaman and Bertram C. Bruce. New York: Peter Lang, pp. 339-54.

Wubbels, Theo, Perry Den Brok, Ietje Veldman, and Jan van Tartwijk. 2006. Teacher interpersonal competence for Dutch secondary multicultural classrooms. Teachers and Teaching: Theory and Practice 12: 407-33. [CrossRef] 
Yin, Robert K. 2003. Case Study Research, 3rd ed. Thousand Oaks: Sage Publications.

Zirkel, Sabrina, and Nancy Cantor. 2004. 50 years after Brown v. Board of Education: The promise and challenge of multicultural education. Journal of Social Issues 60: 1-15. [CrossRef] 